\title{
Spontaneous Resolution of a Traumatic Intracranial Aneurysm
}

\section{Resolução espontânea de aneurisma traumático intracraniano}

\author{
Augusto Santos de Jesus ${ }^{1}$ Bernardo Keuffer Mendonça ${ }^{1}$ Camila Carvalhais Costa ${ }^{2}$ \\ ${ }^{1}$ Neurosurgery Department, Hospital João XXIII, Belo Horizonte, \\ Minas Gerais, Brazil \\ 2 Faculdade de Medicina da Universidade Federal de Minas Gerais, Belo \\ Horizonte, Minas Gerais, Brazil \\ Address for correspondence Camila Carvalhais Costa, 3rd year \\ Medical School, Faculdade de Medicina da Universidade Federal de \\ Minas Gerais, Belo Horizonte, Minas Gerais, Brazil \\ (e-mail: camilacarvalhaisc@gmail.com).
}

Arq Bras Neurocir 2016;35:222-227.
Abstract
Keywords
- brain injuries
- intracranial aneurysm
- craniocerebral trauma
- cerebral angiography
- spontaneous remission
- carotid arteries

\section{Resumo}

Palavras-chave

- traumatismos encefálicos

- aneurisma intracraniano

- traumatismos craniocerebrais

- angiografia cerebral

- remissão espontânea

- artérias carótidas
Traumatic intracranial aneurysms are rare, and normally result from blunt or penetrating head traumas. Carotid angiography is considered the gold standard and reliable exam to detect this aneurysm. There are specific angiography features that mark the contrasts between a traumatic aneurysm and a common saccular aneurysm. Most authors agree that once the diagnosis is made, surgery is the ideal treatment. This article presents a case of a successful expectant treatment based on the clinical findings of the patient and combined with a constant evaluation of her case. The clinical findings depend on the location and direction of growth of the aneurysm. Traumatic aneurysms of the internal carotid artery (ICA) are unusual, and occur predominantly in the intracavernous portion of that vessel.

Aneurismas traumáticos intracranianos são raros, e normalmente resultam de um traumatismo craniano fechado ou penetrante. $\mathrm{O}$ exame considerado padrão ouro para detectar esse tipo de aneurisma é a angiografia da circulação carotídea. Existem características específicas das angiografias que diferenciam o aneurisma traumático do aneurisma sacular comum. A maioria dos autores acredita que, quando realizado o diagnóstico, o melhor tratamento é a cirurgia. O artigo apresenta um caso de tratamento conservador que evolui com sucesso, baseado nos achados clínicos da paciente, e combinado com avaliação constante do caso. Os achados clínicos na paciente dependem da localização e da direção de crescimento do aneurisma. Aneurismas traumáticos da artéria carótida interna $(\mathrm{ACl})$ são raros, e ocorrem predominantemente na sua porção intracavernosa. received

March 7, 2016

accepted

June 8, 2016

published online

August 1, 2016
DOI http://dx.doi.org/

10.1055/s-0036-1586239.

ISSN 0103-5355.
Copyright $(2016$ by Thieme Publicações License terms

Ltda, Rio de Janeiro, Brazil
(요 (1) $\Theta \circledast$ 


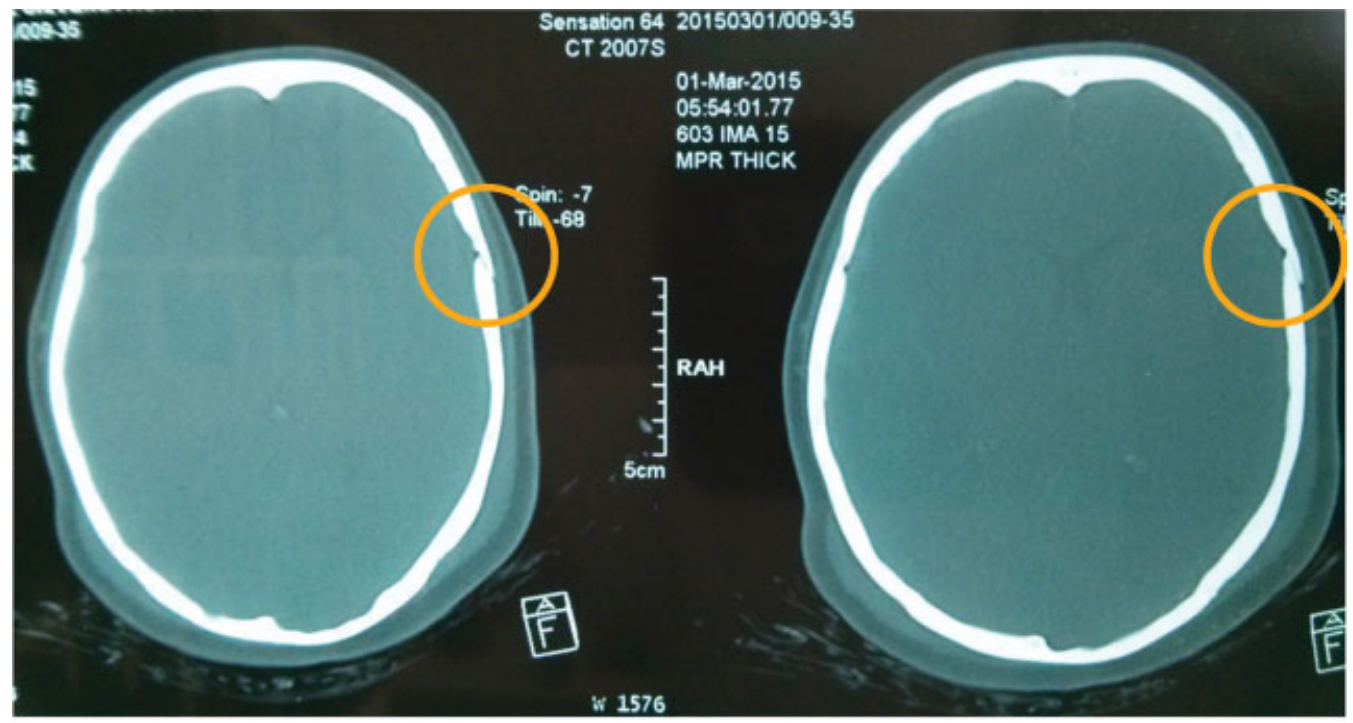

Fig. 1 Computed tomography (CT) indicating a left frontotemporal linear skull fracture (circle).

\section{Introduction}

Traumatic intracranial aneurysms are rare. They constitute only 0.15 to $0.40 \%$ of all intracranial aneurysms, ${ }^{1}$ and are usually located on distal vessels. ${ }^{2,3}$ In one study of 73 traumatic aneurysms, $27 \%$ were located on the meningeal; $40 \%$ on the middle cerebral; and $18 \%$ on the anterior cerebral arteries. ${ }^{2}$ Traumatic aneurysms of the internal carotid artery (ICA) are unusual, and occur predominantly in the intracavernous portion of that vessel. ${ }^{2-4}$ The most common mechanism of injury involving the ICA is the closed head trauma with a basal skull fracture, ${ }^{5}$ which may be associated, in addition to the traumatic aneurysm, with a post-traumatic carotid-cavernous fistula, 5,6 which occurs in $0.2 \%$ of the patients with craniocerebral trauma. ${ }^{5}$
We describe a case of a patient victim of a head trauma that developed a traumatic false aneurysm of the intracavernous portion of the ICA and a low flow post-traumatic carotid-cavernous fistula (CCF).

\section{Case Report}

A 45-year-old woman victim of a motorcycle accident was admitted to our hospital on March 1st 2015. At the site of the accident, she had a Glasgow Coma Scale (GCS) score of 14, which had a downgrade to 10 . When admitted to our service the following day, at the initial neurological exam, her GCS score was 13, and she had anisocoria with fixed mydriasis and otorrhagia on the left pupil. She also presented peripheral facial paralysis on the left side, and retro-orbital headache.

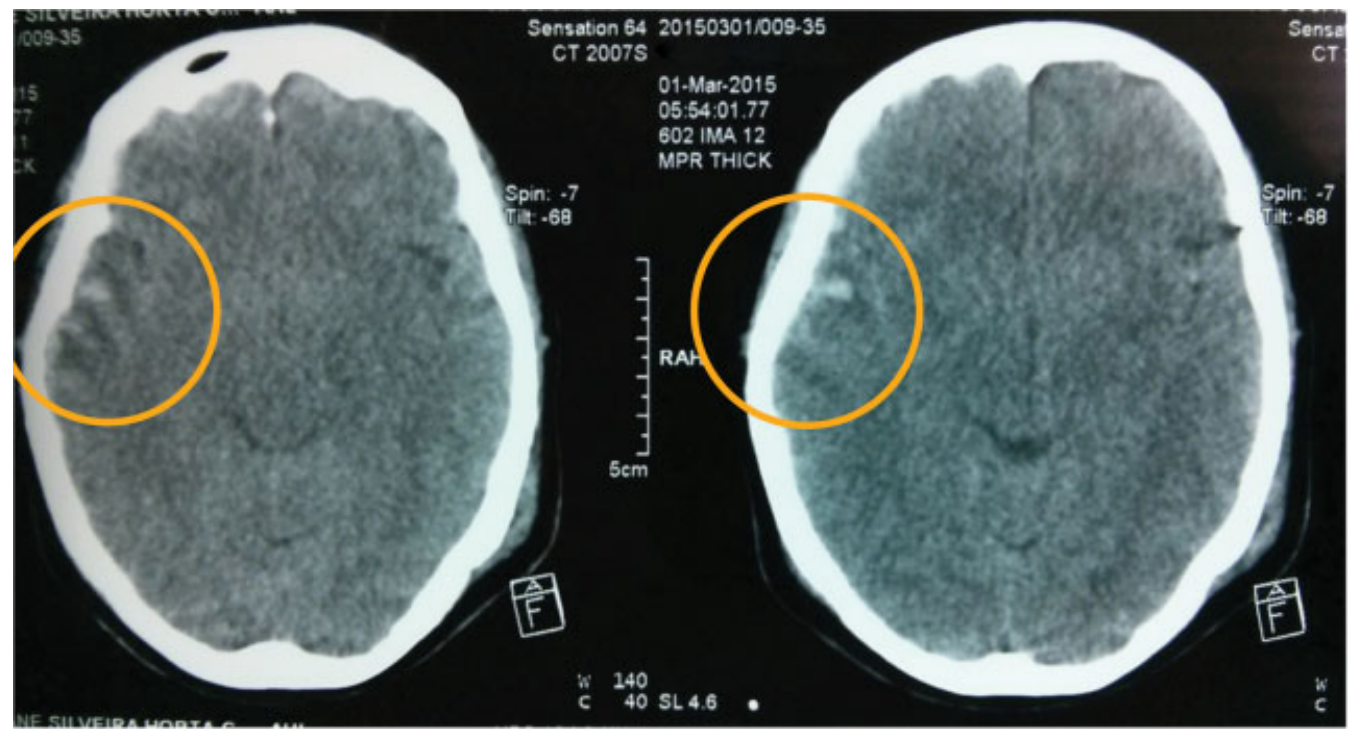

Fig. 2 Computed tomography indicating brain contusion on the right temporal area (circle). 


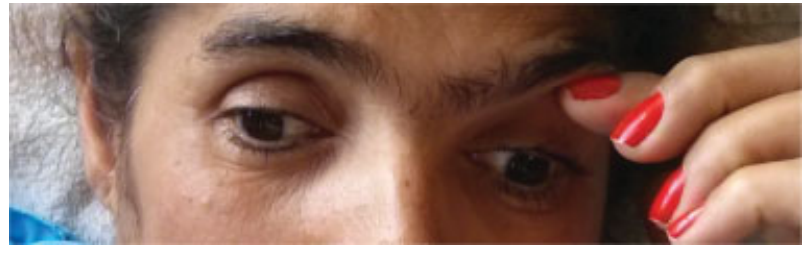

Fig. 3 Ophthalmoplegia.

Computed tomography (CT) demonstrated a left frontotemporal linear skull fracture, and revealed brain contusions on the right temporal area and on the left frontal area (-Figs. 1 and 2 ).

On the 3rd day after the trauma, the patient was alert, aware of time and place, with a GCS score of 15 . The peripheral facial paralysis on the left side, due to the bone fracture, and the retro-orbital headache were still present. The patient also had ophthalmoplegia (-Fig. 3), anisocoria with fixed mydriasis ( - Fig. 4), and eyelid ptosis ( - Fig. 5), all on the left side. Her sensibility on the territories of V1, V2 and V3 was preserved, and she had an absence of epistaxis and chemosis. The otorrhagia had disappeared on that day.

As the symptoms persisted, on the 11th day a CT angiography was performed, and presented stasis and ectasia of the ophthalmic vein on the left eye (-Figs. 6 and 7 ).

On the 13th day after the trauma, the initial cerebral angiogram was prescribed and revealed a small traumatic false aneurysm on the cavernous segment of the ICA (C-4) related to its inferolateral trunk, and a low flow post-traumatic carotid-cavernous fistula (-Fig. 8 and $\mathbf{9}$ ).

After the examination, we opted for expectant management, and decided to make a new evaluation of the patient in ten to fourteen days for better judgment.

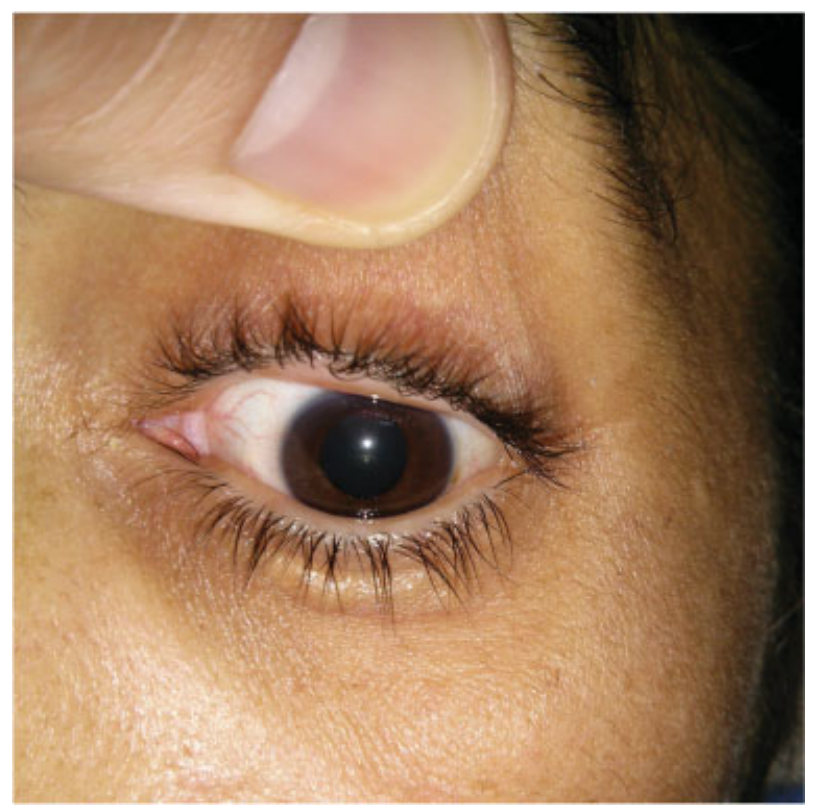

Fig. 4 Anisocoria with fixed mydriasis.

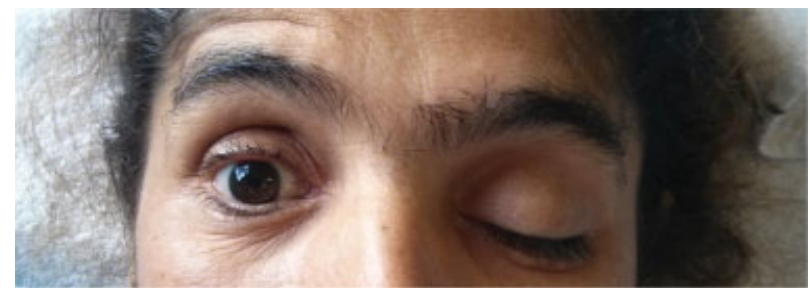

Fig. 5 Eyelid ptosis.

A new cerebral angiogram taken on the 26th day demonstrated an absence of opacification of the false aneurysm and resolution of the CCF ( $\mathbf{- F i g . 1 0}$ and 11). The patient had an improvement of the eyelid ptosis, peripheral facial paralysis and movement of the superior oblique muscle, and did not present headache.

Due to the result of the angiogram and the recovery of the patient, she was discharged from our hospital unit on the 28th day after the trauma.

\section{Discussion}

The first traumatic intracranial aneurysm was reported in $1829 .^{6}$ This type of rare aneurysm normally results from blunt or penetrating head traumas. Iatrogenic damage during intracranial surgery can also be a cause. ${ }^{3,6}$ About $90 \%$ of the cases are associated with skull fracture. ${ }^{3}$ They usually occur within the young male population, which tends to have a higher incidence of traumatic brain injuries (TBI). ${ }^{7}$

Traumatic intracranial aneurysms can be categorized into true, false, dissecting or mixed aneurysms. A true traumatic aneurysm is described as a disruption of the arterial wall with only the adventitia layer left intact. In false aneurysms, there is disruption across all layers of the arterial wall, which is occluded by a hematoma that subsequently makes a fibrous organization and hemodynamic excavation to leave a saccular deformity without any of the arterial wall structures; this hematoma is contained by the arachnoid or brain parenchyma. The dissecting traumatic aneurysm is the formation of a false lumen between the intima and the internal elastica layer. And the mixed traumatic aneurysm results from the post-traumatic rupture of a true aneurysm, which produces a secondary false aneurysm. . $^{2,3,6}$

The clinical findings on the patient depend on the location and direction of the growth of the aneurysm. ${ }^{8}$ The ICA passes through the cavernous sinus, which is a paired complex of venous channels located on the pituitary fossa and on the body of the sphenoid bone, between the endosteal and meningeal layers of the dura. In the lateral wall it contains, from superior to inferior, the oculomotor nerve (cranial nerve [CN] III), the trochlear nerve (cranial nerve CN IV), and the ophthalmic (CN V1) and maxillary divisions of the trigeminal nerve (CN V2). Traversing the sinus, inferolateral to the $\mathrm{C} 4$ segment of the ICA, lies the abducens nerve ( $\mathrm{CN}$ VI). The pituitary gland and the optic chiasm are adjacent to those structures.

When the aneurysm is located on the intracavernous portion of the ICA, the symptoms presented are usually headache, retro-orbital pain, and mass effect due to the 


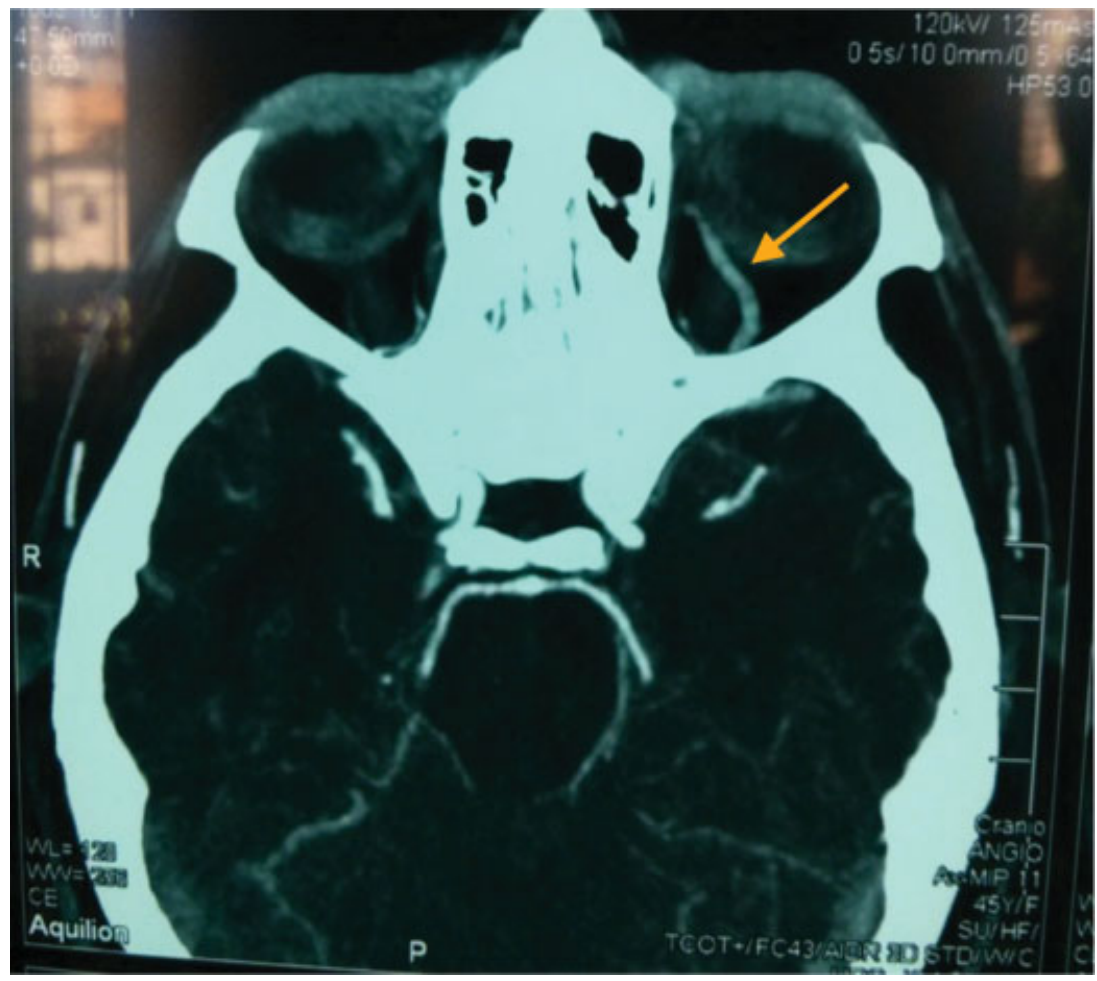

Fig. 6 Computed tomography angiography presenting stasis and ectasia of the left ophthalmic vein (arrow), axial view.

compression of CN III, IV, V1, V2 and VI. ${ }^{9}$ When bleeding occurs, the patient may exhibit the classic triad unilateral blindness, orbital fractures, and massive epistaxis. ${ }^{10}$ Our patient did not presented much of these symptoms, probably due to the low flow of the lesion and its location on the inferolateral trunk of the cavernous ICA.

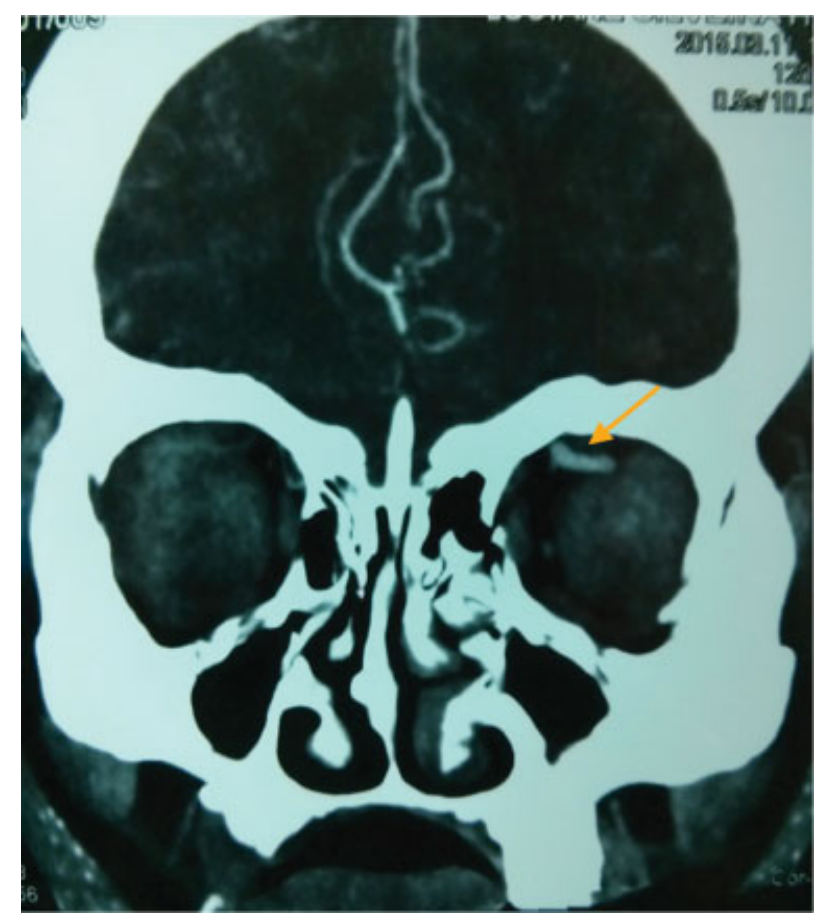

Fig. 7 Computed tomography angiography presenting stasis and ectasia of the left ophthalmic vein (arrow), coronal view.

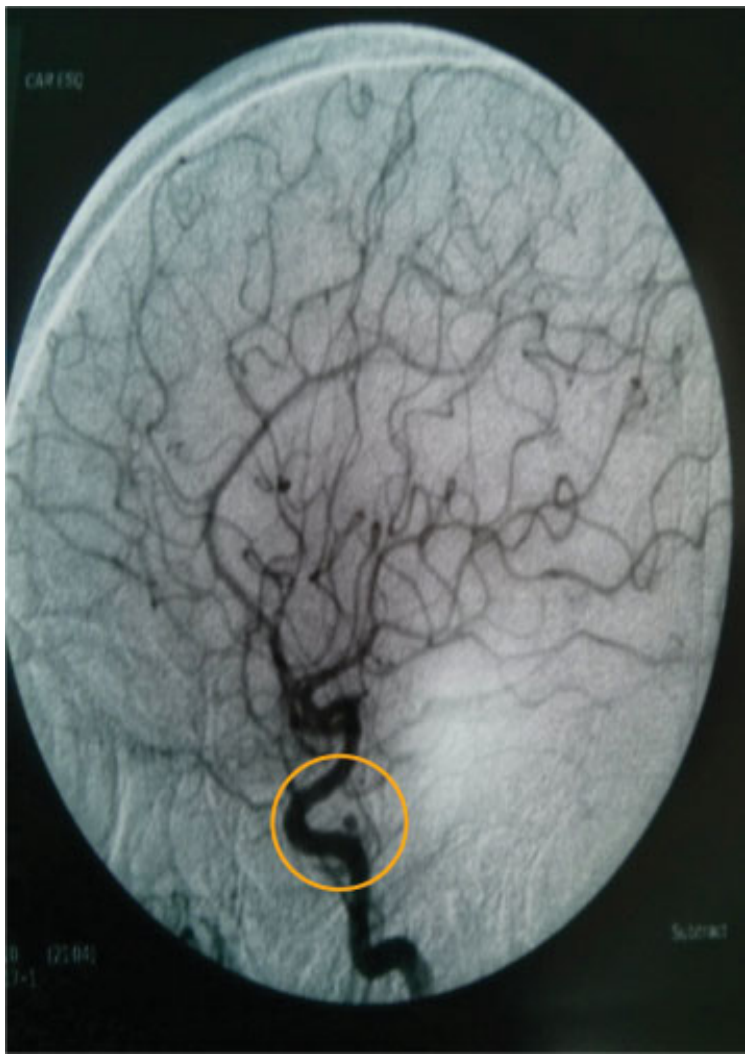

Fig. 8 Cerebral angiogram presenting the traumatic false aneurysm on the cavernous segment of the ICA (C-4) related to its inferolateral trunk and a low flow post-traumatic carotid-cavernous fistula (circle). 


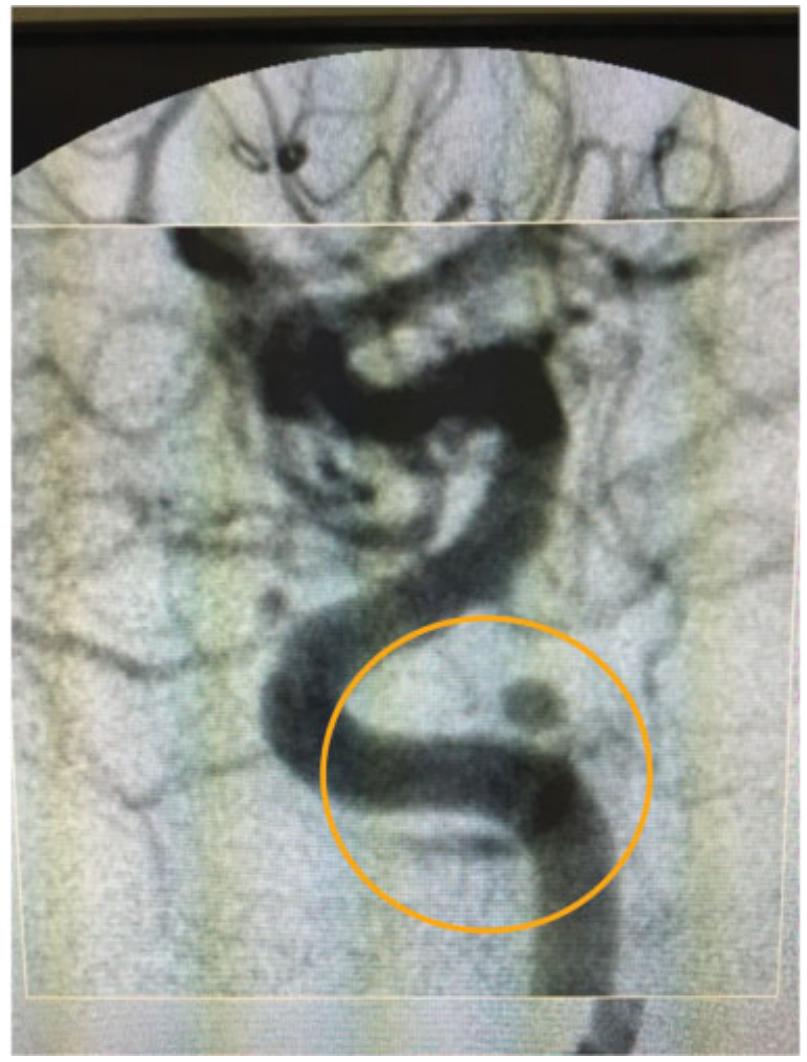

Fig. 9 -Figure 8 zoomed in (circle).

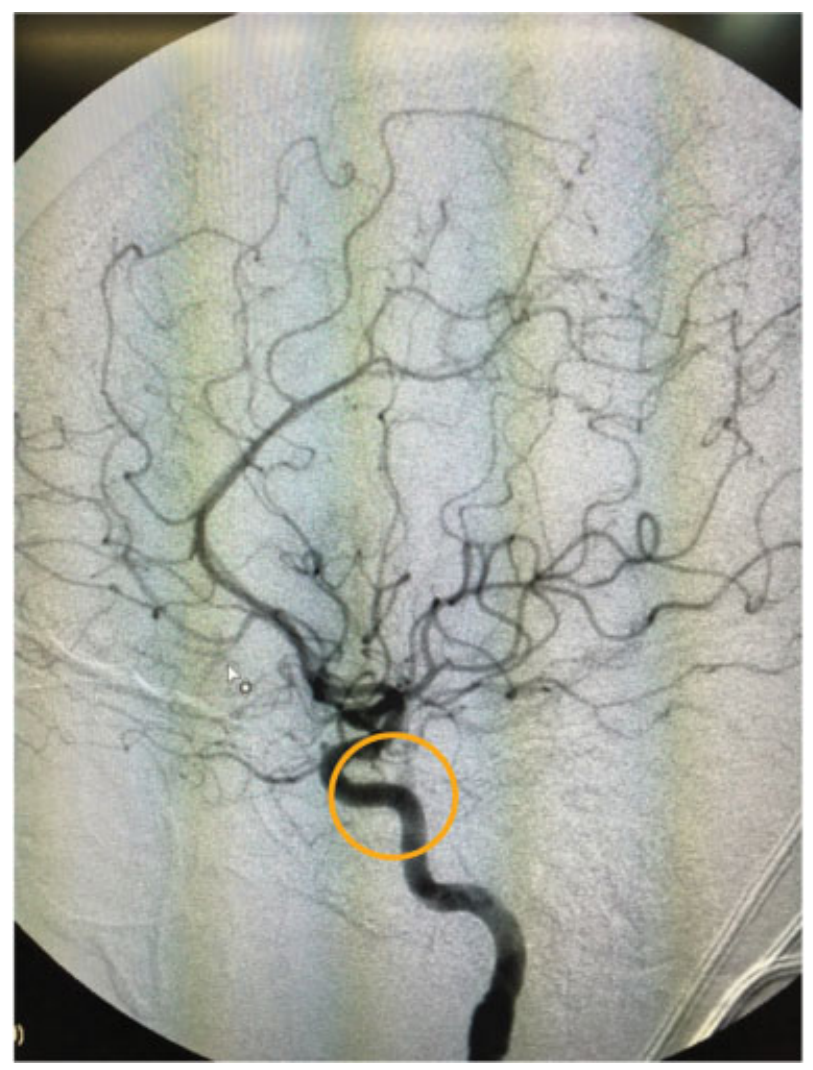

Fig. 10 Cerebral angiogram showing an absence of opacification of the false aneurysm and the resolution of the CCF (circle).

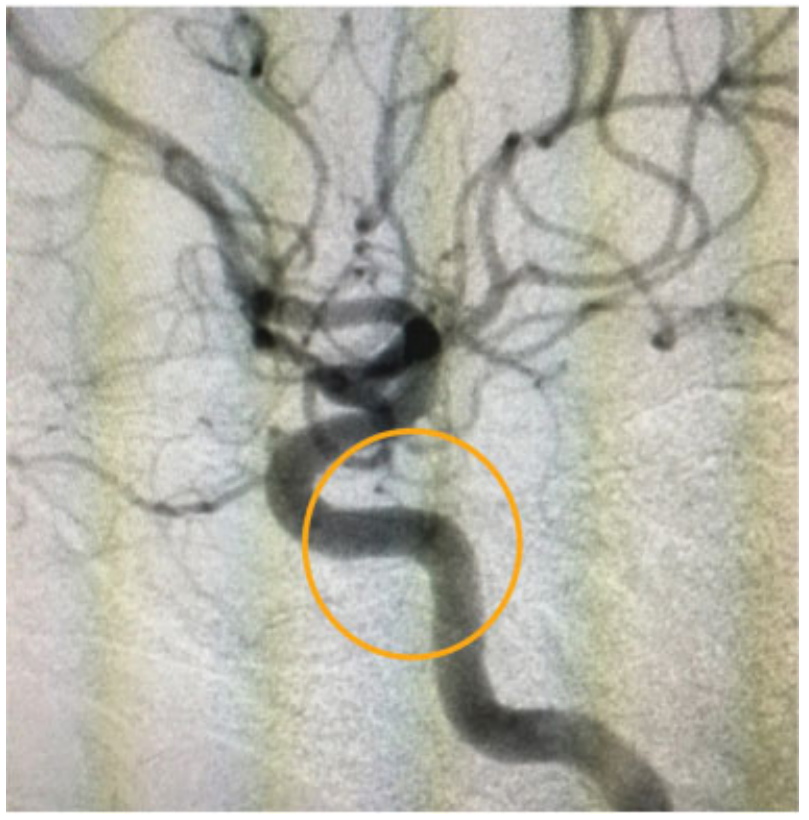

Fig. 11 -Figure 10 zoomed in (circle).

Aside from persistent headache, not always present, and delayed deterioration following the head trauma, few clinical findings point specifically to the diagnosis of traumatic aneurysm. ${ }^{3,6}$ For this reason, radiological diagnosis is essential.

Computed tomography scan and magnetic resonance imaging (MRI) contribute with the initial information to suggest a traumatic aneurysm diagnosis, and a CT or MR angiography can verify it, ${ }^{10}$ even though carotid angiography is considered the gold standard and reliable exam to detect this aneurysm. 2,6,10

There are angiography features that mark the contrasts between a traumatic aneurysm and a common saccular aneurysm. Traumatic aneurysms have slow hemodynamics, with delay filling and emptying. They have an irregular contour, usually don't have the aneurysm neck, and are located far from the branching points of the arteries. ${ }^{1-3,6,11}$

Apart from the high sensibility of this radiological exam in detecting intracranial aneurysms, when performed right after the trauma, an angiography identifies traumatic aneurysms in only $54 \%$ of the cases. ${ }^{1,7}$ Consequently, when an initial angiography does not detect the injury and there is still a suspicion of a traumatic aneurysm, the exam should be repeated two weeks later to confirm the diagnosis. ${ }^{1,7}$

Serial angiography in most cases indicates an enlargement of the lesion, ${ }^{1,3,6,12}$ but it may occasionally demonstrate a decrease in size, or even spontaneous disappearance of it. ${ }^{3,6,12}$ In a 1983 study conducted with 94 patients presenting traumatic intracranial aneurysms, Yokota et $\mathrm{al}^{13}$ reported only 8 cases that lead to spontaneous cure without surgical treatment.

The natural history of this lesion is not well known. ${ }^{6,7}$ Its clinical presentation, the quality of symptoms and their temporal course must be considered in order to treat 
conservatively or invasively an unruptured cavernous carotid artery aneurysm. ${ }^{13}$ That was the case of our patient, who received a non-invasive successful treatment after a general review of her clinical picture.

All therapies share the same objective of lasting elimination of rupture risk and relief of mass effect symptoms. ${ }^{13}$

Traumatic aneurysms of the ICA can be treated surgically, endovascularlly, ${ }^{1,10}$ or managed non-operatively. ${ }^{1,14}$ The surgical mortality rate is $\sim 20 \%$, and the non-operative mortality rate is $\sim 50 \%{ }^{1}$

The surgery or endovascular intervention can be considered deconstructive or reconstructive. ${ }^{10}$ A treatment is considered deconstructive when the affected blood vessel is removed from the circulation, and reconstructive when the injured area is excluded from the vessel but circulation continues. ${ }^{10}$ Surgeries in those cases either give direct access to or bypass the lesion. ${ }^{10}$ A direct approach to this segment of the ICA is challenging due to anatomic restriction, which limits direct operative exposure and distal control. ${ }^{10}$ An endovascular treatment can be performed with coils, stent, covered stent or ICA balloon occlusion. ${ }^{10}$

\section{Conclusion}

Based on the individual presentation of the traumatic aneurysm in our patient, we chose expectant management, and had successful results, with the recovery of the injury.

Most authors agree that surgical treatment is indicated because of the poor clinical history of the traumatic aneurysm. However, it is important to first consider an early diagnosis, since patients who are diagnosed after the rupture present a mortality rate almost three times higher than the ones diagnosed before the rupture. ${ }^{6}$ An early diagnosis can only be reached with a more frequent use of angiography when there is suspicion of traumatic aneurysms.

\section{References}

1 Ohba S, Kuroshima Y, Mayanagi K, et al. Traumatic aneurysm of the supraclinoid internal carotid artery-case report-. Neurol Med Chir (Tokyo) 2009;49(12):587-589

2 Saito K, Baskaya MK, Shibuya M, Suzuki Y, Sugita K. False traumatic aneurysm of the dorsal wall of the supraclinoid internal carotid artery-case report. Neurol Med Chir (Tokyo) 1995;35(12):886-891

3 Tindall GT, Cooper PR, Barrow DL. The practice of neurosurgery, Vol II. Baltimore: Williams \& Wilkins; 1996

4 Sarmento Junior K, Oliveira RF, Bem Neto AS, Acocella A, Bellizzi $\mathrm{CM}$. Aneurisma intracavernoso de carótida interna pós-traumático: manifestações típicas e atípicas. Congresso Triológico Otorrinolaringol 2005

5 Greenberg MS. Handbook of neurosurgery. 4th edition. Lakeland: Greenberg Graphics; 1997

6 Parkinson D, West M. Traumatic intracranial aneurysms. J Neurosurg 1980;52(1):11-20

7 Gonçalves Neto DG, Aguiar GB, Veiga JCE, et al. Pseudoaneurisma traumático da artéria meníngea média tratado por via endovascular. Arquivos Brasileiros de Neurocirurgia 2013;32(1):51-56

8 Akai F, Nakagawa S, Fukawa T, Yugami H, Taneda M. Symptomatic cavernous internal carotid artery aneurysms treated with detachable coils. Interv Neuroradiol 2003;9(Suppl 1):89-94

9 Higashida RT, Halbach VV, Dowd C, et al. Endovascular detachable balloon embolization therapy of cavernous carotid artery aneurysms: results in 87 cases. J Neurosurg 1990;72(6):857-863

10 Zanini MA, Tahara A, Santos GS, et al. Pseudoaneurysm of the internal carotid artery presenting with massive (recurrent) epistaxes: a life-threatening complication of craniofacial trauma. Arq Neuropsiquiatr 2008;66(2A):268-271

11 Beena NV, Kishore MS, Mahale A, Poornima V. Pseudoaneurysm of internal carotid artery. Indian J Pediatr 2007;74(3):307-309

12 Parkinson D. Surgical Management of traumatic intracranial aneurysms. In: Schmidek HH, Sweet WH, editors. Operative Neurosurgical Techniques, Vol 1. 3rd edition. Philadephia: W. B. Saunders Company; 1995:1127-31

13 Yokota H, Tazaki H, Murayama K, et al. [Traumatic cerebral aneurysm: 94 cases from the literature and 5 cases observed by the authors]. No Shinkei Geka 1983;11(5):521-528

14 Eddleman CS, Hurley MC, Bendok BR, Batjer HH. Cavernous carotid aneurysms: to treat or not to treat? Neurosurg Focus 2009;26(5):E4 